\title{
Synthesis of Silicon Nanoparticles and Nanowires by a Nontransferred Arc Plasma System
}

\author{
Sooseok Choi, ${ }^{1}$ Hyunjun Lee, ${ }^{2}$ and Dong-Wha Park ${ }^{2}$ \\ ${ }^{1}$ Department of Nuclear and Energy Engineering, Jeju National University, Jeju 63243, Republic of Korea \\ ${ }^{2}$ Department of Chemistry and Chemical Engineering and Regional Innovation Center for Environmental Technology of \\ Thermal Plasma (RIC-ETTP), Inha University, Incheon 22212, Republic of Korea
}

Correspondence should be addressed to Dong-Wha Park; dwpark@inha.ac.kr

Received 21 July 2016; Accepted 6 September 2016

Academic Editor: Xiaopeng Li

Copyright (C) 2016 Sooseok Choi et al. This is an open access article distributed under the Creative Commons Attribution License, which permits unrestricted use, distribution, and reproduction in any medium, provided the original work is properly cited.

\begin{abstract}
Silicon nanomaterials were synthesized from solid silicon powder in microsize using a nontransferred arc plasma system. Synthesized silicon nanomaterials were sphere or wire in morphology according to the input power of arc plasma, the flow rate of plasma forming gas, and the collecting position of product. The product was spherical nanoparticles at a high input power for complete evaporation, while it was nanowires at a relatively low input power. The mean diameter of synthesized silicon nanoparticles was increased from $20.52 \mathrm{~nm}$ to $40.01 \mathrm{~nm}$ by increasing the input power from $9 \mathrm{~kW}$ to $13 \mathrm{~kW}$. On the other hand, the diameter of silicon nanowires was controllable by changing the flow rate of plasma forming gas. The mean diameter of silicon nanowires was increased from $16.69 \mathrm{~nm}$ to $23.03 \mathrm{~nm}$ by decreasing the plasma forming gas flow rate from $15 \mathrm{~L} / \mathrm{min}$ to $12 \mathrm{~L} / \mathrm{min}$.
\end{abstract}

\section{Introduction}

The photovoltaic (PV) and microelectronic industries have maintained over $30 \%$ of annual growth rate [1]. This industrial growth brings about a rapid increase in the production of silicon wafers. Silicon kerf loss is generated during wafer production processes such as block cutting and wafer sawing [2]. The amount of kerf loss in wafer production processes increases with the growth of silicon industry, though the kerf loss is considered as industrial waste. In order to save cost and to reduce energy consumption, lots of processes for the purification and the recycling of silicon kerf loss have been studied. They include superconducting magnetic separation [3], fractional melting [4], directional solidification [5], plasma oxidation [6], and electromagnetic separation [7] to recover highly purified silicon from silicon kerf loss. In addition, many researches have been studied to reuse silicon kerf loss and purified silicon $[8,9]$.

Nanostructured silicon material has various advantages in an integrated circuit (IC) and microfabrication technology. Therefore, many researchers have synthesized silicon nanomaterial by well-known methods such as nonthermal plasma processing using silicon tetrachloride and silane precursors $[10,11]$, the decomposition of silane and organosilane in gas phase reactions $[12,13]$, and liquid phase method with silicides precursors [14]. However, the preparation of silicon nanomaterial from solid phase is limited. It is because the vaporization of solid phase silicon materials requires considerable energy density. Silicon has a high latent heat for vaporization and a low thermal conductivity compared with typical metal. Moreover, the thermal conductivity of solid state silicon decreases with increasing temperature [15]. As a result, there is a limitation to prepare silicon nanomaterial from the evaporation of silicon in solid state.

Thermal plasma processing has been used to prepare nanomaterials with various advantages [16-18]. The high enthalpy of thermal plasma improves reaction kinetics and chemical reactivity. Thermal plasma has the region containing balanced charges of electrons and heavy particles such as radicals, ions, and neutrals with high temperature in local thermodynamic equilibrium [19]. Such active species allow the vaporization of any kind of raw material easily. Moreover, the rapid quenching of thermal plasma leads to the production of nanoparticles. 


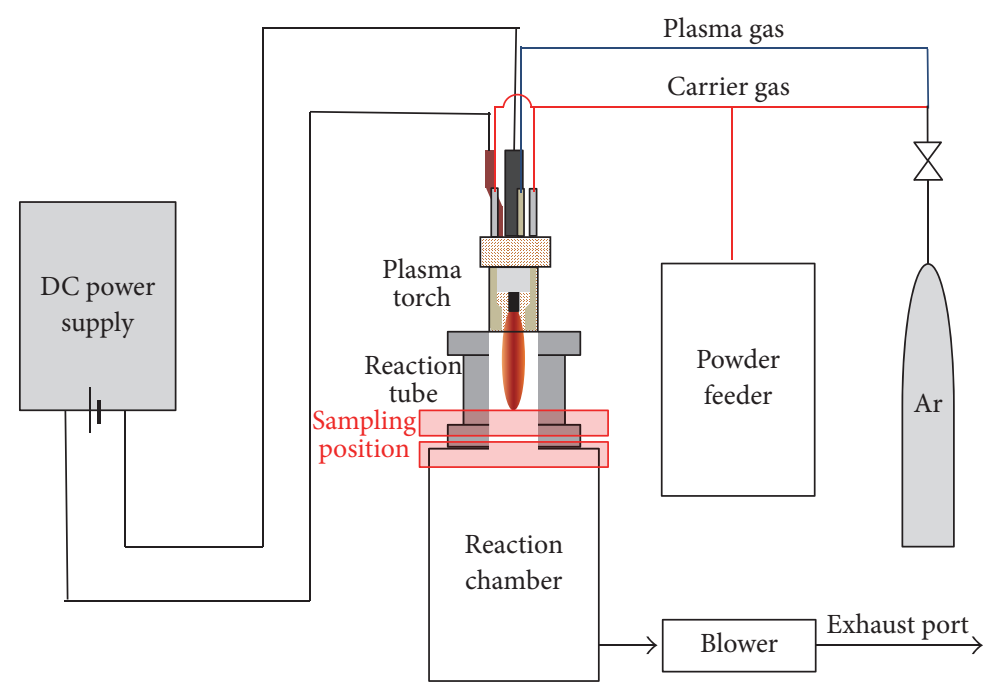

FIGURE 1: Schematic diagram of the arc thermal plasma system for the synthesis of silicon nanomaterial.

The arc thermal plasma system was used for the preparation of silicon nanomaterials with high productivity at a low cost [20]. The aim of this study is to investigate the synthesis of silicon nanomaterials from the vaporization of microsized silicon raw material. The vaporization of silicon feedstock was controlled by changing the plasma input power and the flow rate of plasma forming gas. In the product, both of nanosized silicon particles and wires were found. The formation routes for nanoparticles or nanowires were suggested from experimental results.

\section{Experimental}

The experimental equipment consists of a direct current (DC) power supply, a powder feeder, a plasma torch, a reaction tube, and a reaction chamber. The reaction tube maintains high temperature atmosphere after the ejection of thermal plasma jet at the torch exit, and the reaction is completed at the reaction chamber. Figure 1 is a schematic diagram of the arc thermal plasma system for the synthesis of silicon nanomaterial. The input power provided by the DC power supply was controlled at 7, 9, 11, and $13 \mathrm{~kW}$, respectively. The flow rate of plasma forming argon gas was changed from $12 \mathrm{~L} / \mathrm{min}$ to $15 \mathrm{~L} / \mathrm{min}$ to control the velocity of plasma jet. The feeding rate and the argon carrier gas flow rate for the feeding of raw silicon powder were fixed at $0.2 \mathrm{~g} / \mathrm{min}$ and $5 \mathrm{~L} / \mathrm{min}$, respectively. In the whole experiment, the arc thermal plasma system was operated at atmospheric pressure. The operating condition is summarized at Table 1.

Silicon nanomaterial was synthesized in the nontransferred arc plasma system from commercial silicon powder ( $40 \mu \mathrm{m}$, Aldrich, USA). Figures 2 and 3 are the field emission scanning electron microscopy (FE-SEM) images and the $\mathrm{X}$ ray diffractometer (XRD) pattern of the silicon raw material. Figure 2 shows that angular silicon powder has broad size distribution and irregular shapes. Figure 3 indicates that peaks positions of XRD patterns have 2 theta values of
TABLE 1: Operating condition of the arc thermal plasma system for the synthesis of silicon nanomaterial.

\begin{tabular}{lc}
\hline Input power & $7,9,11$, and $13 \mathrm{~kW}$ \\
Plasma gas flow rate & Ar 12 and $15 \mathrm{~L} / \mathrm{min}$ \\
Raw material & Silicon, $40 \mu \mathrm{m}$ \\
Carrier gas & Ar $5 \mathrm{~L} / \mathrm{min}$ \\
Powder feed rate & $0.2 \mathrm{~g} / \mathrm{min}$ \\
Operating pressure & $101.3 \mathrm{kPa}$ \\
Sampling position & Reaction tube and chamber cover \\
\hline
\end{tabular}

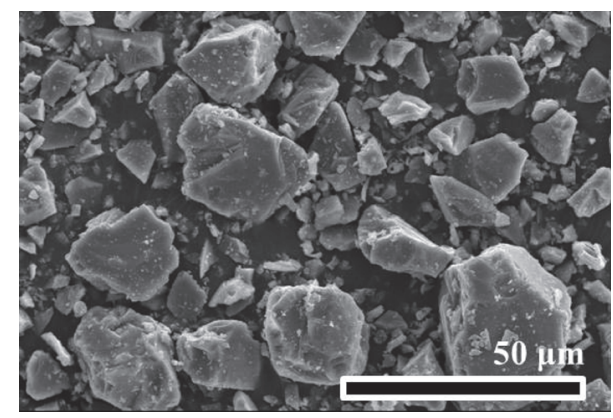

FIGURE 2: SEM image of silicon raw material.

$28.45 \mathrm{~cm}^{-1}, 47.31 \mathrm{~cm}^{-1}$, and $56.14 \mathrm{~cm}^{-1}$ corresponding to the crystal planes of (111), (220), and (311), respectively.

The injected raw powder into thermal plasma was vaporized by high temperature of thermal plasma jet and generating silicon nuclei, followed by the production of nanomaterial with rapid quenching. Products were collected from the inner surface of the reaction tube and the chamber cover, respectively. The morphology of silicon nanomaterial was analyzed by field emission scanning electron microscopy (FESEM, S-4300, Hitachi, Japan), and the size of nanomaterial was measured by an image process software (Image-Pro Plus, Media Cybernetics, USA). In addition, the phase of the 


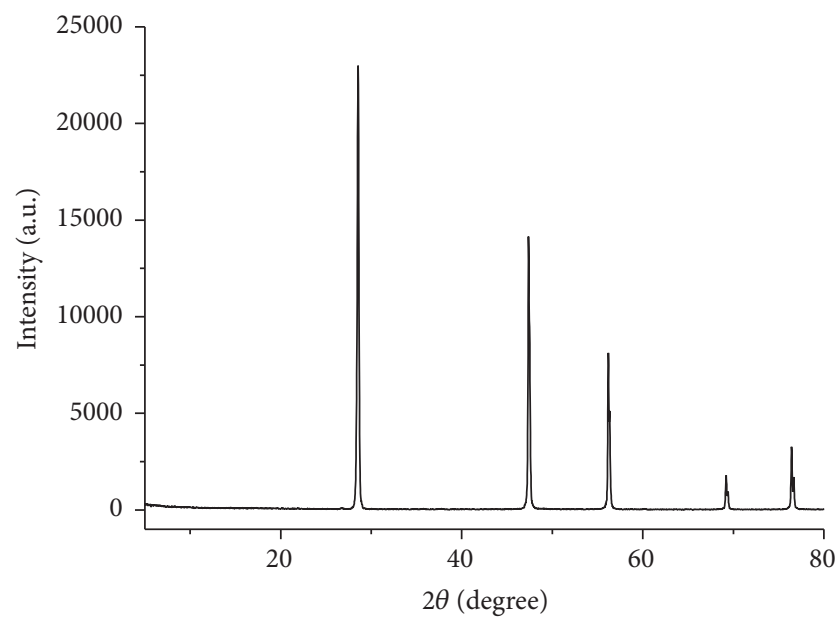

FIgURE 3: XRD spectrum of silicon raw material.

product was identified by X-ray diffractometry (XRD, DMAX 2500, Rigaku, Japan).

\section{Results and Discussion}

3.1. The Effect of the Sampling Position. Figure 4 shows SEM images of products sampled at the reaction tube with different magnifications in the condition of $13 \mathrm{~kW}$ for the input power and $15 \mathrm{~L} / \mathrm{min}$ for the flow rate of plasma forming gas. The product is composed of two different sizes of spherical particles. Figure 4(a) shows microsized particles, while Figure 4(b) shows nanoparticles condensed on the surface of a microsized particle [21]. Figure 5 shows SEM images of products sampled at the chamber cover in the condition of $13 \mathrm{~kW}$ for the input power and $15 \mathrm{~L} / \mathrm{min}$ for the flow rate of plasma forming gas. Figure 5(a) shows well dispersed small products in contrast to Figure 4(a). These images show that the quantity of microsized particles at the chamber cover is smaller than those at the reaction tube. It is because more raw materials were vaporized along with the plasma flame. Therefore, sufficiently long residence time is required to vaporize the silicon raw materials completely.

Figure 6 shows the XRD patterns of raw material and synthesized silicon nanomaterials in the condition of $13 \mathrm{~kW}$ for the input power and $15 \mathrm{~L} / \mathrm{min}$ for the flow rate of plasma forming gas. Figure 6 indicates that there are differences between the intensities of the silicon raw material and the synthesized nanomaterials. The silicon nanomaterials collected at the reaction tube and the chamber cover have low crystallinity compared with the silicon raw material. It is because the crystallization of product occurred with the growth of nanoparticles after vaporization in thermal plasma flow. From the same position of characteristic peaks, however, the physical phase of the product is the same with the raw material.

Average grain sizes of the raw material and products are estimated by the Scherrer equation from the full width at half maximum of XRD patterns [21]

$$
d=\frac{k \lambda}{B \cos \theta} \text {. }
$$

TABLE 2: Mean particle sizes at the chamber cover in different input powers of 9,11 , and $13 \mathrm{~kW}$ at the fixed plasma forming gas flow rate of $15 \mathrm{~L} / \mathrm{min}$.

\begin{tabular}{cccc}
\hline & Raw material & $\begin{array}{c}\text { Product at reaction } \\
\text { tube }\end{array}$ & $\begin{array}{c}\text { Product at } \\
\text { chamber cover }\end{array}$ \\
\hline Grain size & $40.98 \mathrm{~nm}$ & $34.13 \mathrm{~nm}$ & $29.26 \mathrm{~nm}$ \\
\hline
\end{tabular}

The grain size, $d$, can be calculated by the Scherrer constant $(k)$, the wavelength of X-ray $(\lambda)$, diffraction angle $(\theta)$, and the corrected full width at half maximum $(B)$. Table 2 indicates the average grain size of the silicon raw material and products collected at the reaction tube and the reaction chamber prepared in the condition of $13 \mathrm{~kW}$ for the input power and $15 \mathrm{~L} / \mathrm{min}$ for the flow rate of plasma forming gas. Calculated results show that the grain size of product from the reaction tube is larger than that from the chamber cover, while the particle size is the opposite results as shown in Figures 4(b) and 5(b). It is explained by a high temperature atmosphere with a strong radiation from thermal plasma in the reaction tube. Therefore, the crystallization of the silicon nanoparticles takes place after the formation of nanoparticles as well as during particle growth in the reaction tube. On the other hand, fabricated silicon nanoparticles at the chamber cover are relatively far from the plasma radiation leading to relatively weak intensities of characteristic peaks in XRD pattern.

3.2. The Effect of the Input Power. Figure 7 is a low resolution SEM image of fabricated silicon nanomaterials sampled at the chamber cover in different input powers of 7,9 , and $11 \mathrm{~kW}$ at the fixed plasma forming gas flow of $15 \mathrm{~L} / \mathrm{min}$. Figure 7 shows that microsized silicon raw material was partially vaporized. These images also show that the morphology of products is similar to the raw material. In comparison to Figure 5(a), the input power of $13 \mathrm{~kW}$ is required for the complete evaporation of silicon raw material. Figure 8 is a high magnification SEM image at the same condition with Figure 7. Most of products is nanosized spherical particles, while some of them are nanowires. Figure 8(a) was synthesized in the condition of $7 \mathrm{~kW}$ for the input power and it shows spherical nanoparticles. Figures 8(b) and 8(c), however, show silicon nanomaterials with nanowires and nanoparticles. Hafiz et al. explained the synthesis mechanism of silicon nanowire which is produced in two-step processes using hypersonic plasma particle deposition with $\mathrm{TiSi}_{2}$ catalyst [22], and Meshram et al. introduced the synthesis method of silicon nanowire using tin catalyst in a hot wire chemical vapor process [23]. On the other hand, metal catalyst was not used in the present work. Instead of the catalyst, the influences of the plasma flow on wire formation were hypothesized when the nontransferred arc thermal plasma system is employed to produce silicon nanomaterial. Silicon raw material is partially vaporized in the reaction tube due to a high velocity of plasma jet [24]. Therefore, surface evaporation takes place in the reaction tube, and viscid molten silicon is expected in core region. As a result, it is hypothesized that the viscid molten silicon droplets are stretched by the momentum transfer from the 


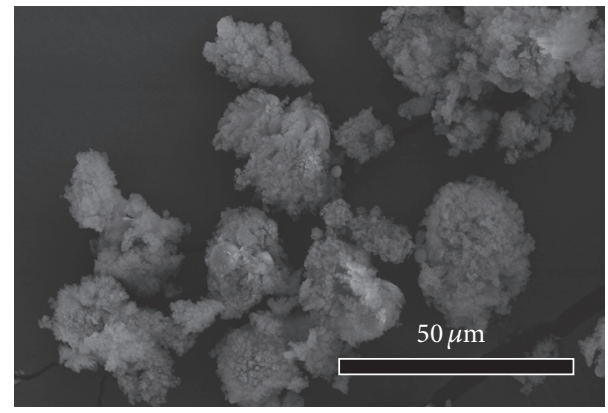

(a)

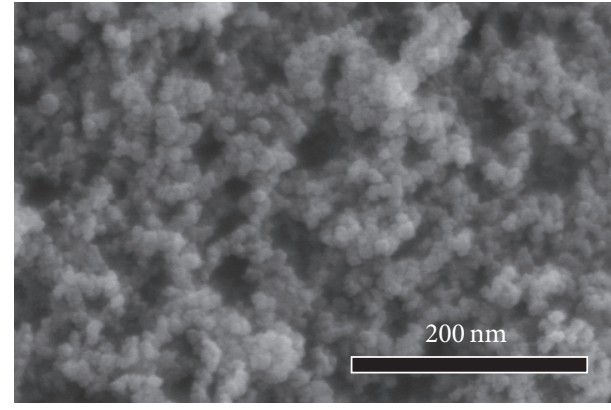

(b)

FIGURE 4: SEM images of products sampled at the reaction tube wall with different magnification rates of (a) 1,000x and (b) 100,000x at 13 kW for the input power and at $15 \mathrm{~L} / \mathrm{min}$ for the flow rate of plasma forming gas.

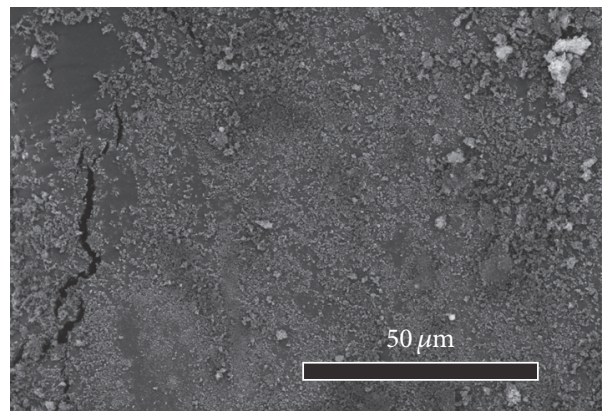

(a)

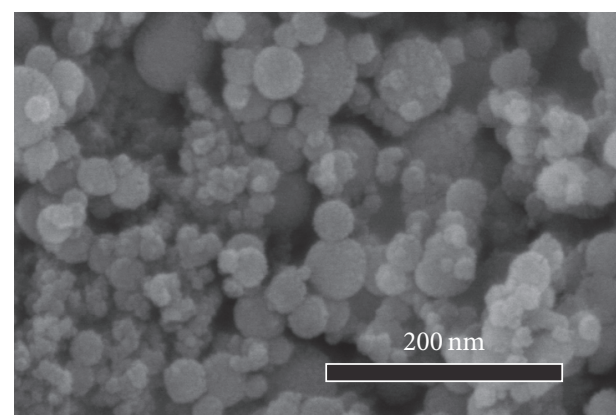

(b)

FIGURE 5: SEM images of products sampled at the chamber cover with different magnification rates of (a) 1,000x and (b) 100,000x at 13 kW for the input power and at $15 \mathrm{~L} / \mathrm{min}$ for the flow rate of plasma forming gas.

high velocity of thermal plasma jet forming the wire structure of silicon.

The wire structured silicon is frequently observed at the condition of $11 \mathrm{~kW}$ for the input power rather than at the condition of $9 \mathrm{~kW}$. There are two reasons to support such result. The first one is the low viscosity of the molten silicon in the case of $11 \mathrm{~kW}$ in comparison with the case of $9 \mathrm{~kW}$. The viscosity of the molten silicon material is decreased with increasing the silicon temperature [25]. The other is the high plasma velocity. The velocity of thermal plasma at the condition of $11 \mathrm{~kW}$ for the input power is faster than that at $9 \mathrm{~kW}$ [24]. The velocity of thermal plasma jet has influence on the acceleration and stretching of molten silicon particles. Therefore, it is supposed that the wire structure is formed effectively at $11 \mathrm{~kW}$ with the low viscosity of molten silicon and the high velocity of thermal plasma jet.

Figure 8(c) shows silicon nanoparticles as well as silicon nanowires. When the silicon raw materials passed the plasma jet in the high temperature region, the silicon nanoparticles were formed by the vaporization and condensation processes [21, 26-29]. On the other hand, some nanoparticles were formed after the formation of nanowires. A low thermal conductivity of silicon compared with typical metal hinders the internal heat transfer of silicon. The surface vaporization of silicon wire occurred by the energy stored in the molten wire. This silicon vapor prepared by the surface vaporization
TABLE 3: Mean particle size at the chamber cover in different input powers of 9,11 , and $13 \mathrm{~kW}$.

\begin{tabular}{cccc}
\hline & $9 \mathrm{~kW}$ & $11 \mathrm{~kW}$ & $13 \mathrm{~kW}$ \\
Particle mean size & $20.52 \mathrm{~nm}$ & $35.61 \mathrm{~nm}$ & $40.01 \mathrm{~nm}$ \\
\hline
\end{tabular}

was nucleated, and then spherical nanoparticles were condensed. On the other hand, only spherical nanoparticles were observed in Figure 5(b) at the highest input power of $13 \mathrm{~kW}$. In this case, enough energy was supplied for the complete evaporation of the raw materials within the residence time. This sufficient energy for full vaporization of the silicon materials was supplied by the high plasma gas temperature in the case of $13 \mathrm{~kW}$ for the input power [30].

Figure 9 shows the particle size distribution of nanoparticles collected at the chamber at three different input powers of 9,11 , and $13 \mathrm{~kW}$. The particle size distribution is relatively narrow at the condition of $9 \mathrm{~kW}$ for the input power. On the other hand, the particle size distribution is broad at the condition of $13 \mathrm{~kW}$. The size distribution of the nanoparticles increases by increasing the arc plasma input power. Table 3 is the particle mean size sampled at the chamber cover at different input powers of 9,11 , and $13 \mathrm{~kW}$. The particle mean sizes were $20.52 \mathrm{~nm}, 35.61 \mathrm{~nm}$, and $40.01 \mathrm{~nm}$ at $9 \mathrm{~kW}, 11 \mathrm{~kW}$, and $13 \mathrm{~kW}$ for the input powers, respectively. The particle mean size increases depending on the amount of silicon vapor 
TABLE 4: Thermal properties of copper, aluminum, silicon, and alumina.

\begin{tabular}{lcccc}
\hline & $\mathrm{Cu}$ & $\mathrm{Al}$ & $\mathrm{Si}_{2}$ & $\mathrm{Al}_{2} \mathrm{O}_{3}$ \\
\hline Melting point $\left({ }^{\circ} \mathrm{C}\right)$ & 1,085 & 660 & 1,414 & 3,265 \\
Boiling point $\left({ }^{\circ} \mathrm{C}\right)$ & 2,562 & 2,470 & 3,000 \\
Heat of fusion $(\mathrm{J} / \mathrm{g})$ & 205 & 387 & 1,800 & 1093 \\
Heat of vaporization $(\mathrm{J} / \mathrm{g})$ & 5,234 & 9,462 & 10,614 & - \\
Thermal conductivity $(\mathrm{W} / \mathrm{m} \cdot \mathrm{K})$ & 385 & 210 & 124 \\
\hline
\end{tabular}

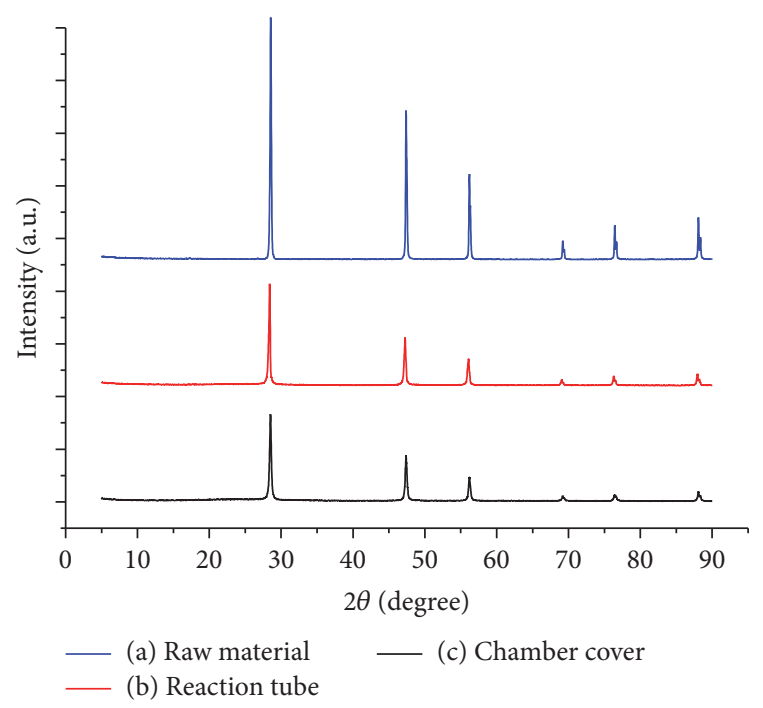

FIGURE 6: XRD spectrum of (a) raw material and products sampled (b) at the reaction tube and (c) at the chamber cover prepared in the condition of $13 \mathrm{~kW}$ for the input power and $15 \mathrm{~L} / \mathrm{min}$ for the flow rate of plasma forming gas.

in the reactor. The quantity of silicon vapor is determined by the plasma input power at a fixed raw material feeding. More heat is transferred to feeding powder at the highest input power of $13 \mathrm{~kW}$, and then the amount of the silicon vapor in the reactor is increased [31]. Such large amount of silicon vapor in a high input power leads to the supersaturation of the silicon at a high temperature. The nucleation of the silicon vapor is affected by supersaturation of silicon vapor at a high temperature, and nucleated silicon materials in a high power have a long residence time to condense into silicon nanoparticles. Such tendencies result in the broad particle size distribution and the large mean size of the silicon nanoparticles [29]. A small amount of silicon is vaporized at the surface of silicon materials at a low input power condition. Such silicon vapor produces silicon nanoparticles with a small mean diameter attached to the surface of partially evaporated microsized silicon materials.

3.3. The Effect of the Flow Rate of Plasma Forming Gas. Figure 10 is the SEM image of the synthesized silicon product collected at the chamber cover. Thermal plasma was operated at $11 \mathrm{~kW}$ for the input power and $12 \mathrm{~L} / \mathrm{min}$ for the flow rate of plasma forming gas. In this condition, the flow rate of plasma forming argon gas was decreased compared with the operating condition for Figure 8(c). The velocity of plasma flame is decreased by decreasing the gas flow rate from $15 \mathrm{~L} / \mathrm{min}$ to $12 \mathrm{~L} / \mathrm{min}$. The average diameter of silicon nanowire was $16.69 \mathrm{~nm}$ at the flow rate of $15 \mathrm{~L} / \mathrm{min}$. On the other hand, silicon nanowires produced at $12 \mathrm{~L} / \mathrm{min}$ were $23.03 \mathrm{~nm}$ in average diameter. This result indicates that the formation of the nanowires is affected by the plasma velocity. The average diameter of the silicon nanowires was decreased with increasing the plasma velocity.

3.4. Synthesis Mechanism of Silicon Structure. Nanoparticles are produced through the homogeneous nucleation and heterogeneous condensation when the vaporization and condensation processes are considered. The first step of the process is the vaporization of the raw material by the high enthalpy of the arc thermal plasma. Feeding particles move along the plasma flow to the tail of the plasma jet. The temperature of the plasma flow is rapidly decreased transferring the energy to the raw material. The vapor is saturated by such quenching process. Therefore, the homogeneous nucleation and heterogeneous condensation are followed, and this series of process results in the production of nanoparticles [21, 2629].

Silicon nanoparticles and nanowires were fabricated in this study. It is hypothesized that this phenomenon is caused by unique properties of silicon such as a high thermal conductivity compared to the metal materials, large latent heat, and a high vaporization point. In addition, the synthesis of the silicon nanomaterials is affected by the unique characteristics of the rapid quenching of arc thermal plasma. Figure 11 explains a synthesis mechanism of silicon nanomaterial by arc thermal plasma. Figure 11(a) shows the process that the silicon nanoparticles are synthesized when raw material is fully evaporated. Silicon vaporizes steadily due to a low thermal conductivity and a high vaporization enthalpy. The raw material can be fully evaporated with a sufficient heat transfer from thermal plasma. The supersaturated silicon vapor is prepared by the decrease of the silicon vapor temperature with the rapid quenching rate. This supersaturated silicon vapor is nucleated to produce stable phase. After the nucleation process, the growth is followed through the heterogeneous condensation. Therefore, silicon nanoparticles are fabricated by vaporization and condensation process.

Table 4 shows the thermal properties of copper, aluminum, silicon, and alumina. Copper and aluminum have favorable conditions to be vaporized, because the latent heat of metal is lower than that of silicon, and the thermal conductivity of metal is higher than that of silicon. The 


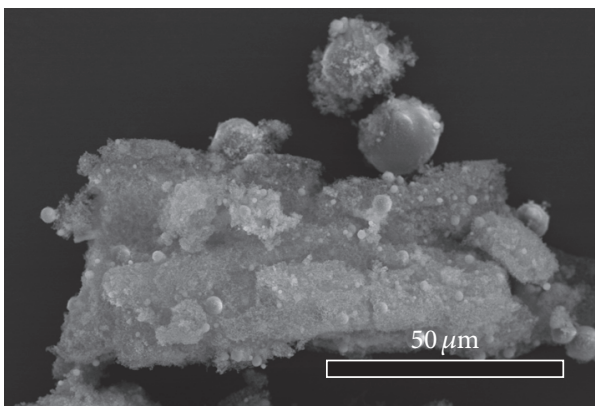

(a)

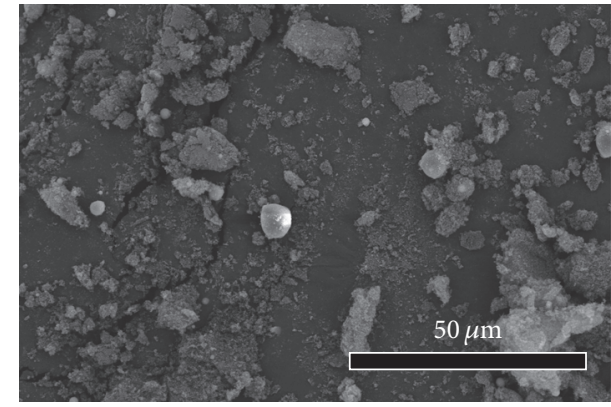

(b)

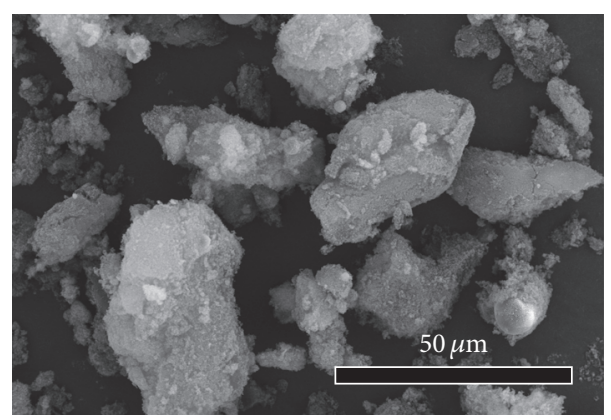

(c)

FIGURE 7: Low magnification SEM images at 1,000x for products sampled at the chamber cover in different input powers of (a) $7 \mathrm{~kW}$, (b) $9 \mathrm{~kW}$, and (c) $11 \mathrm{~kW}$ at the fixed plasma forming gas flow rate of $15 \mathrm{~L} / \mathrm{min}$.

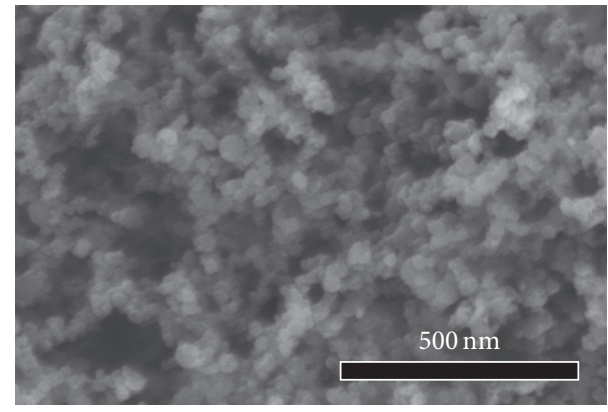

(a)

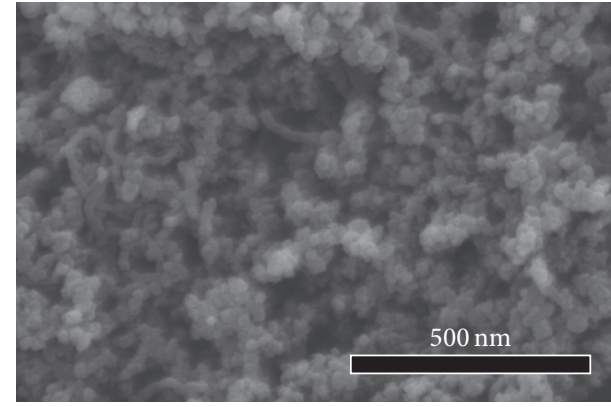

(b)

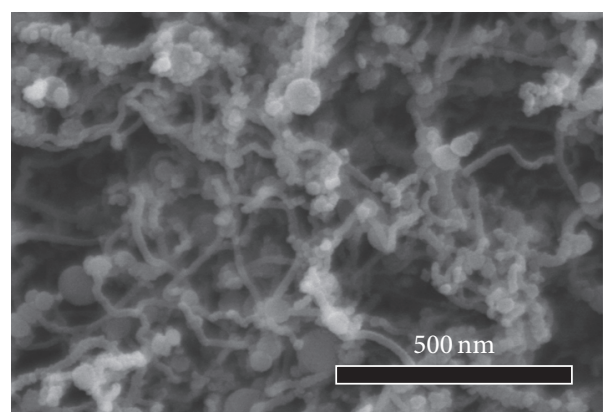

(c)

FIGURE 8: High magnification SEM images at 100,000x for products sampled at the chamber cover in different input powers of (a) $7 \mathrm{~kW}$, (b) $9 \mathrm{~kW}$, and (c) $11 \mathrm{~kW}$ at the fixed plasma forming gas flow rate of $15 \mathrm{~L} / \mathrm{min}$. 


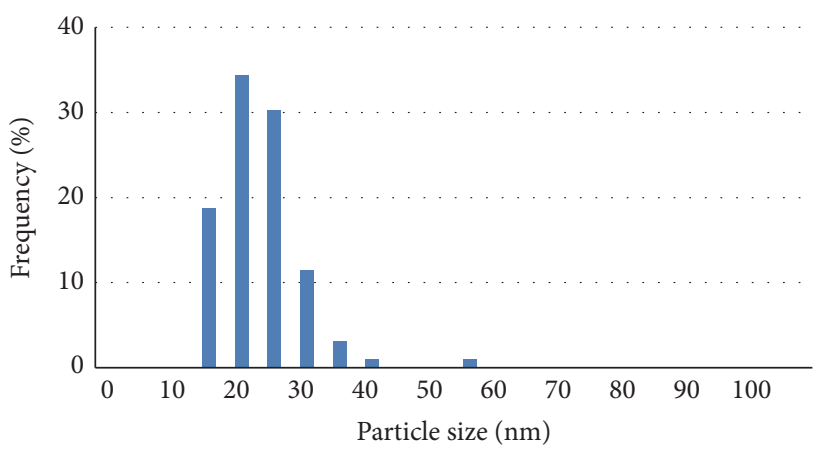

(a)

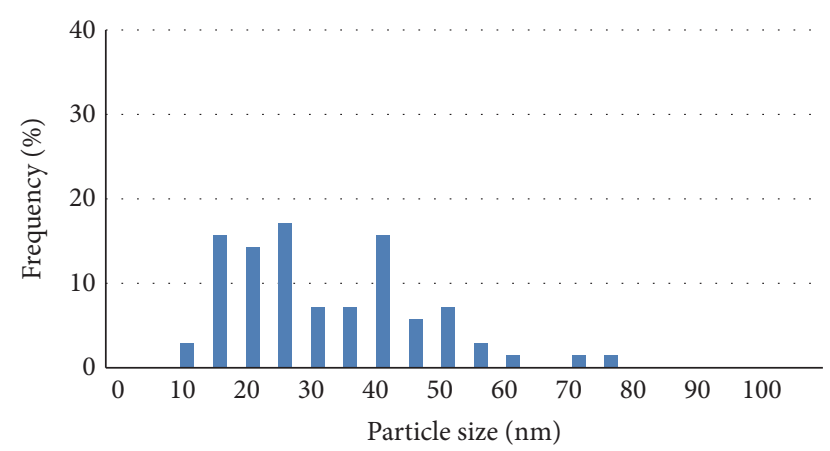

(b)

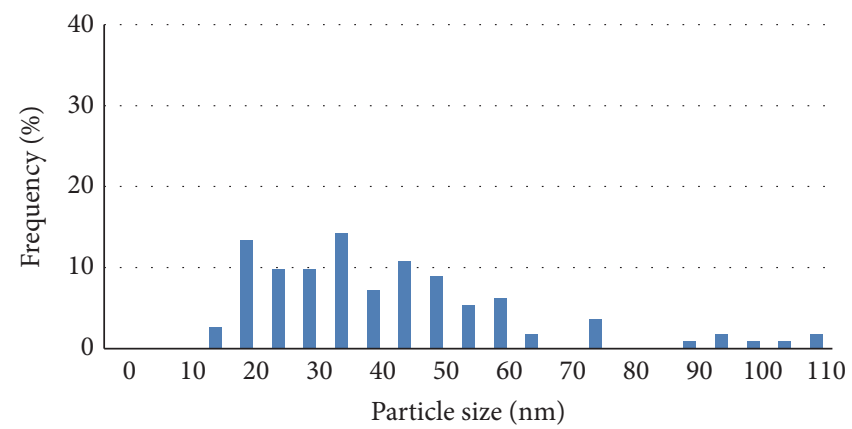

(c)

Figure 9: Particle size distributions of products sampled at the chamber cover in different input powers of (a) $9 \mathrm{~kW}$, (b) $11 \mathrm{~kW}$, and (c) $13 \mathrm{~kW}$ at the fixed plasma forming gas flow rate of $15 \mathrm{~L} / \mathrm{min}$.

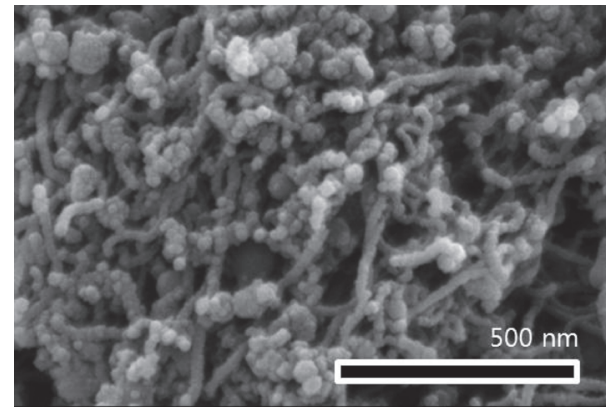

FIGURE 10: SEM image of product sampled at the chamber cover at $11 \mathrm{~kW}$ for the input power and at $12 \mathrm{~L} / \mathrm{min}$ for the flow rate of plasma forming gas.

synthesis of nanomaterials has been studied by an enough enthalpy and a high temperature of thermal plasma for the complete evaporation. Alumina which is ceramic material has lower thermal conductivity than that of silicon and metals. The spheroidization of the ceramic material has been studied by the melting of ceramic material using a thermal plasma system $[32,33]$. Silicon material has the thermal properties between metal material and ceramic material. Therefore, silicon is vaporized more slowly than metal and silicon is believed in both of liquid and gas states in thermal plasma region. Figure 11(b) shows the suggestion of silicon nanowire formation. Silicon raw materials received a certain amount of heat passing through thermal plasma jet in melting state.
The viscosity of molten silicon which is partially vaporized is decreased with increasing its temperature by heat transfer from thermal plasma, and viscid molten silicon starts to be evaporated from surface. Such heated viscid silicon droplets get momentum by a rapid velocity of plasma gas flow and deform the shape of the viscid molten silicon to the wire structure. Therefore, silicon nanowires are produced when the molten silicon nanowires are cooled down by the rapid quenching of thermal plasma jet.

\section{Conclusion}

Silicon nanomaterial was synthesized by the nontransferred arc thermal plasma system. The solid silicon powder with $40 \mu \mathrm{m}$ size was used as raw material. Nontransferred arc thermal plasma was required for the vaporization of the silicon material because silicon materials have a low thermal conductivity and high latent heat. Treated silicon nanomaterial products from the chamber cover were nanoparticles and nanowires. The formation mechanism of silicon nanomaterial suggested that the synthesis of the nanowire is affected by the viscosity and the flow rate of the plasma forming argon gas. Therefore, the diameter of the nanowires was increased from $16.69 \mathrm{~nm}$ to $23.03 \mathrm{~nm}$ with decreasing the flow rate of plasma forming gas. On the other hand, only silicon nanoparticle was found at $13 \mathrm{~kW}$ for input power and at $15 \mathrm{~L} / \mathrm{min}$ for gas flow rate. It was hypothesized that the silicon nanowires are synthesized by the strain of molten silicon with a low thermal conductivity, and the series of the fabrication 


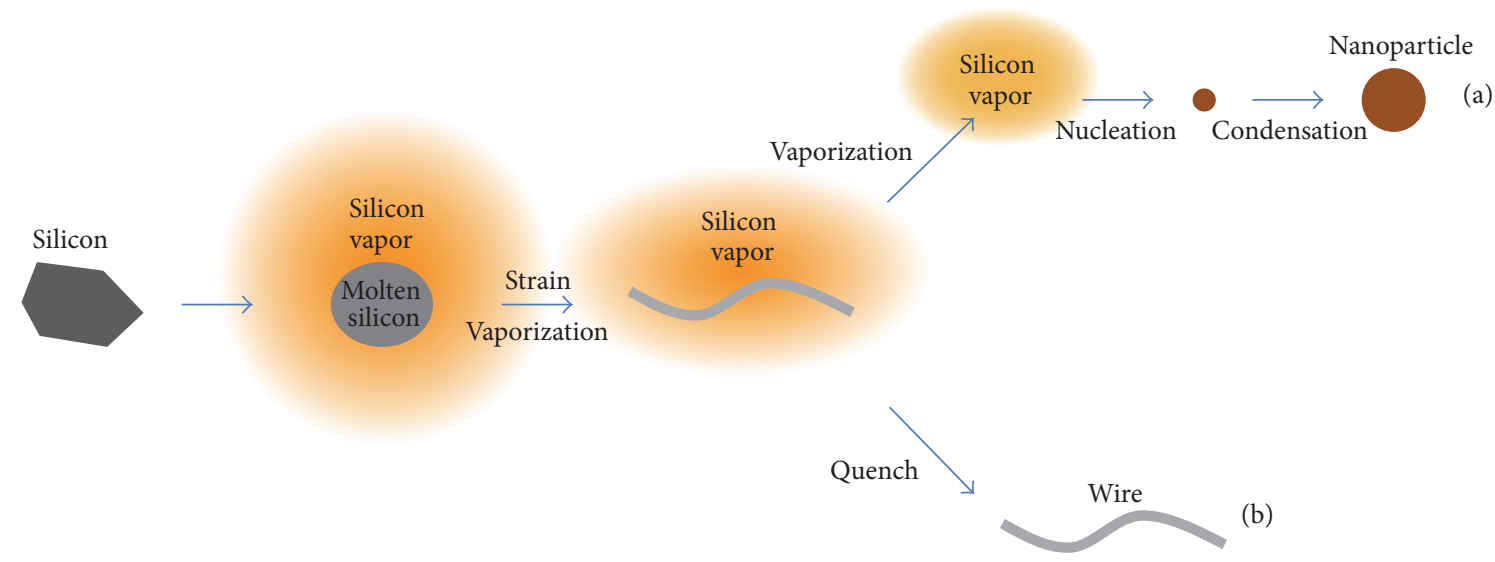

FIGURE 11: Synthesis mechanism of silicon nanowires and nanoparticles form microsized silicon powder in the thermal plasma jet.

of the silicon nanowires is affected by the rapid velocity of the plasma forming gas, when the raw silicon materials were not sufficiently vaporized. Contrary to this, when the raw silicon materials were fully vaporized in the condition of $13 \mathrm{~kW}$ for the input power, only spherical silicon nanoparticles were fabricated from the silicon vapor by the vaporizationcondensation process. Therefore, sufficient heat transfer from thermal plasma to silicon is required to synthesize silicon nanoparticles. Since the working gas influences heat transfer, researches about working gas species and gas injection method to control silicon nanosized products will be carried out as future work. In addition, effect of operating condition on properties of silicon nanomaterials will be studied for practical application of silicon nanomaterials from silicon kerf loss.

\section{Competing Interests}

The authors declare that they have no competing interests.

\section{Acknowledgments}

This work was supported by the Regional Innovation Center for Environmental Technology of Thermal Plasma (ETTP) at INHA University, Korea, designated by the Ministry of Trade, Industry and Energy (2016), and by the Basic Science Research Program through the National Research Foundation of Korea (NRF) funded by the Ministry of Education of the Republic of Korea (no. NRF-2010-0020077).

\section{References}

[1] N. B. Mason, "Industry developments that sustain the growth of crystalline silicon PV output," in Proceedings of the Photovoltaic Science, Applications \& Technology Conference, pp. 4346, Durham, UK, March 2007.

[2] Y.-C. Lin, T.-Y. Wang, C.-W. Lan, and C. Y. Tai, "Recovery of silicon powder from kerf loss slurry by centrifugation," Powder Technology, vol. 200, no. 3, pp. 216-223, 2010.

[3] S. Nishijima, Y. Izumi, S.-I. Takeda, H. Suemoto, A. Nakahira, and S.-I. Horie, "Recycling of abrasives from wasted slurry by superconducting magnetic separation," IEEE Transactions on Applied Superconductivity, vol. 13, no. 2, pp. 1596-1599, 2003.

[4] W. Lee, W. Yoon, and C. Park, "Purification of metallurgicalgrade silicon in fractional melting process," Journal of Crystal Growth, vol. 312, no. 1, pp. 146-148, 2009.

[5] T. Y. Wang, Y. C. Lin, C. Y. Tai, R. Sivakumar, D. K. Rai, and C. W. Lan, "A novel approach for recycling of kerf loss silicon from cutting slurry waste for solar cell applications," Journal of Crystal Growth, vol. 310, no. 15, pp. 3403-3406, 2008.

[6] N. Yuge, M. Abe, K. Hanazawa et al., "Purification of metallurgical-grade silicon up to solar grade," Progress in Photovoltaics: Research and Applications, vol. 9, no. 3, pp. 203-209, 2001.

[7] A. Kolin, "An electromagnetokinetic phenomenon involving migration of neutral particles," Science, vol. 117, no. 3032, pp. 134-137, 1953.

[8] A. Dong, L. Zhang, and L. N. W. Damoah, "Beneficial and technological analysis for the recycling of solar grade silicon wastes," JOM, vol. 63, no. 1, pp. 23-27, 2011.

[9] T. Y. Wang, Y. C. Lin, C. Y. Tai, C. C. Fei, M. Y. Tseng, and C. W. Lan, "Recovery of silicon from kerf loss slurry waste for photovoltaic applications," Progress in Photovoltaics: Research and Applications, vol. 17, no. 3, pp. 155-163, 2009.

[10] K. Shinoda, H. Murakami, Y. Sawabe, and K. Saegusa, "Ultrafast production of silicon via aluminothermic reduction of tetrachlorosilane in a thermal plasma jet," Chemical Engineering Journal, vol. 198-199, pp. 61-64, 2012.

[11] O. Yasar-Inceoglu, T. Lopez, E. Farshihagro, and L. Mangolini, "Silicon nanocrystal production through non-thermal plasma synthesis: a comparative study between silicon tetrachloride and silane precursors," Nanotechnology, vol. 23, no. 25, Article ID 255604, 2012.

[12] X. Li, Y. He, S. S. Talukdar, and M. T. Swihart, "Process for preparing macroscopic quantities of brightly photoluminescent silicon nanoparticles with emission spanning the visible spectrum," Langmuir, vol. 19, no. 20, pp. 8490-8496, 2003.

[13] M. L. Ostraat, J. W. De Blauwe, M. L. Green, L. D. Bell, H. A. Atwater, and R. C. Flagan, "Ultraclean two-stage aerosol reactor for production of oxide-passivated silicon nanoparticles for novel memory devices," Journal of the Electrochemical Society, vol. 148, no. 5, pp. G265-G270, 2001.

[14] D. Neiner, H. W. Chiu, and S. M. Kauzlarich, "Low-temperature solution route to macroscopic amounts of hydrogen terminated 
silicon nanoparticles," Journal of the American Chemical Society, vol. 128, no. 34, pp. 11016-11017, 2006.

[15] P. D. Maycock, "Thermal conductivity of silicon, germanium, III-V compounds and III-V alloys," Solid State Electronics, vol. 10, no. 3, pp. 161-168, 1967.

[16] T. S. Ko, S. Yang, H. C. Hsu et al., "ZnO nanopowders fabricated by dc thermal plasma synthesis," Materials Science and Engineering B, vol. 134, no. 1, pp. 54-58, 2006.

[17] K. Ostrikov and A. B. Murphy, "Plasma-aided nanofabrication: where is the cutting edge?" Journal of Physics D: Applied Physics, vol. 40, no. 8, pp. 2223-2241, 2007.

[18] S.-M. Ko, S.-M. Koo, W.-S. Cho, K.-T. Hwnag, and J.-H. Kim, "Synthesis of SiC nano-powder from organic precursors using RF inductively coupled thermal plasma," Ceramics International, vol. 38, no. 3, pp. 1959-1963, 2012.

[19] M. I. Boulos, P. Fauchais, and E. Pfender, Theraml Plasmas: Fundamentals and Applications, Plenum Press, New York, NY, USA, 1994.

[20] M. Tanaka and T. Watanabe, "Vaporization mechanism from Sn-Ag mixture by Ar- $\mathrm{H}_{2}$ Arc for nanoparticle preparation," Thin Solid Films, vol. 516, no. 19, pp. 6645-6649, 2008.

[21] Z.-Q. Wei, T.-D. Xia, J. Ma et al., "Growth mechanism of $\mathrm{Cu}$ nanopowders prepared by anodic arc plasma," Transactions of Nonferrous Metals Society of China (English Edition), vol. 16, no. 1, pp. 168-172, 2006.

[22] J. Hafiz, R. Mukherjee, X. Wang et al., "Nanoparticle-coated silicon nanowires," Journal of Nanoparticle Research, vol. 8, no. 6, pp. 995-1002, 2006.

[23] N. Meshram, A. Kumbhar, and R. O. Dusane, "Synthesis of silicon nanowires using tin catalyst by hot wire chemical vapor processing," Materials Research Bulletin, vol. 48, no. 6, pp. 22542258, 2013.

[24] T. H. Kim, S. Choi, and D. W. Park, "Numerical simulation on the influence of water spray in thermal plasma treatment of $\mathrm{CF}_{4}$ gas," Current Applied Physics, vol. 12, no. 2, pp. 509-514, 2012.

[25] M. J. Assael, I. J. Armyra, J. Brillo, S. V. Stankus, J. Wu, and W. A. Wakeham, "Reference data for the density and viscosity of liquid Cadmium, Cobalt, Gallium, Indium, Mercury, Silicon, Thallium, and Zinc," Journal of Physical and Chemical Reference Data, vol. 41, no. 3, Article ID 033101, 2012.

[26] S. L. Girshick and C.-P. Chiu, "Homogeneous nucleation of particles from the vapor phase in thermal plasma synthesis," Plasma Chemistry and Plasma Processing, vol. 9, no. 3, pp. 355369, 1989.

[27] S. L. Girshick and C.-P. Chiu, "Kinetic nucleation theory: a new expression for the rate of homogeneous nucleation from an ideal supersaturated vapor," The Journal of Chemical Physics, vol. 93, no. 2, pp. 1273-1277, 1990.

[28] M. Shigeta and A. B. Murphy, "Thermal plasmas for nanofabrication," Journal of Physics D: Applied Physics, vol. 44, no. 17, Article ID 174025, 2011.

[29] N. Kobayashi, Y. Kawakami, K. Kamada et al., "Spherical submicron-size copper powders coagulated from a vapor phase in RF induction thermal plasma," Thin Solid Films, vol. 516, no. 13, pp. 4402-4406, 2008.

[30] T.-H. Kim, S. Choi, and D.-W. Park, "Effects of $\mathrm{NH}_{3}$ flow rate on the thermal plasma synthesis of AlN nanoparticles," Journal of the Korean Physical Society, vol. 63, no. 10, pp. 1864-1870, 2013.

[31] G. Shanmugavelayutham, V. Selvarajan, P. V. A. Padmanabhan, K. P. Sreekumar, and N. K. Joshi, "Effect of powder loading on the excitation temperature of a plasma jet in DC thermal plasma spray torch," Current Applied Physics, vol. 7, no. 2, pp. 186-192, 2007.

[32] V. Chaturvedi, P. V. Ananthapadmanabhan, Y. Chakravarthy et al., "Thermal plasma spheroidization of aluminum oxide and characterization of the spheroidized alumina powder," Ceramics International, vol. 40, no. 6, pp. 8273-8279, 2014.

[33] Z. Károly and J. Szépvölgyi, "Plasma spheroidization of ceramic particles," Chemical Engineering and Processing: Process Intensification, vol. 44, no. 2, pp. 221-224, 2005. 

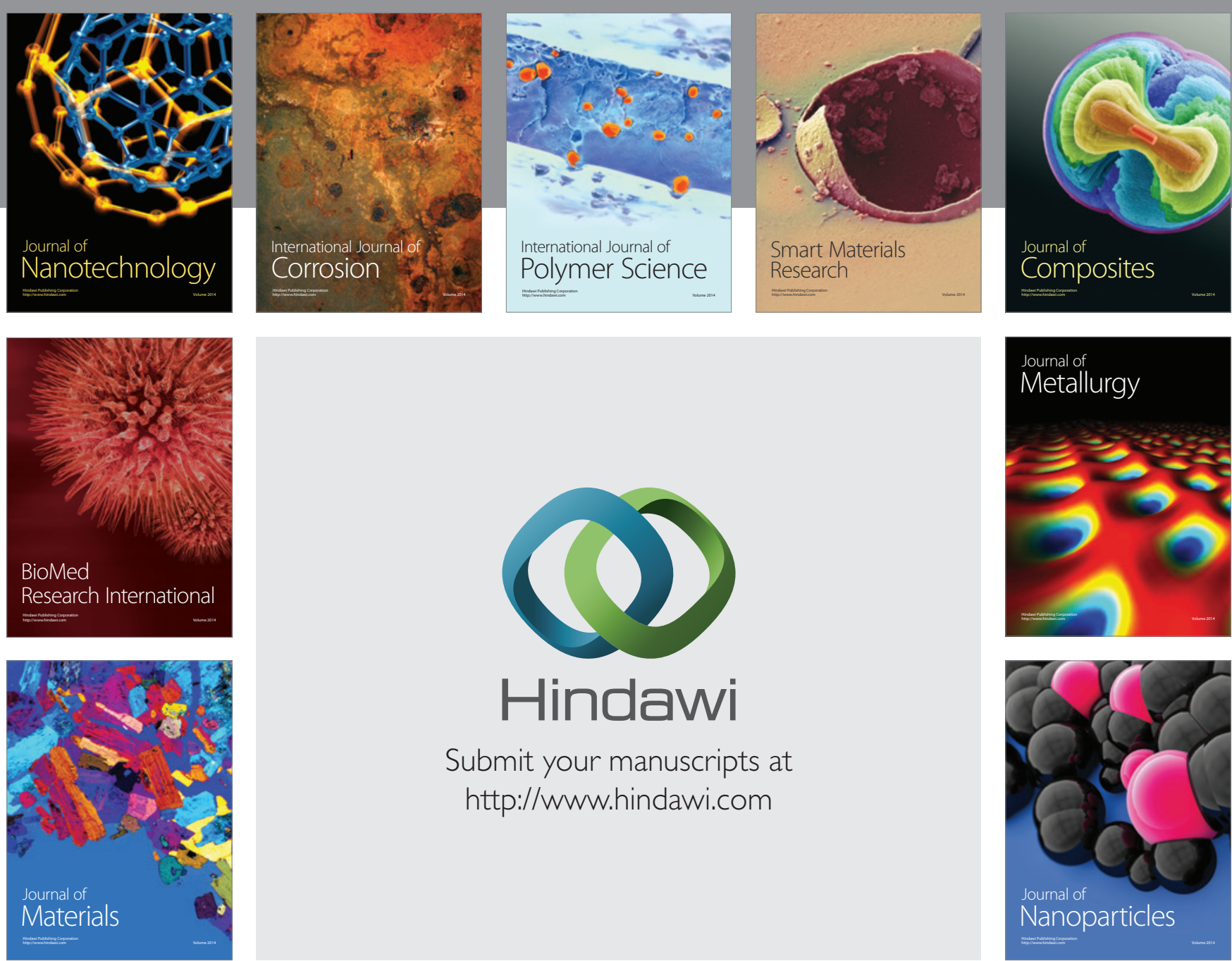

\section{Hindawi}

Submit your manuscripts at

http://www.hindawi.com

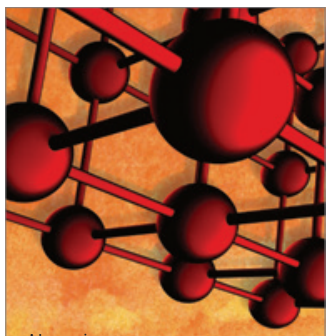

Materials Science and Engineering
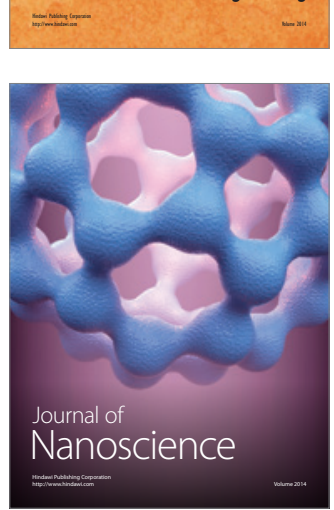
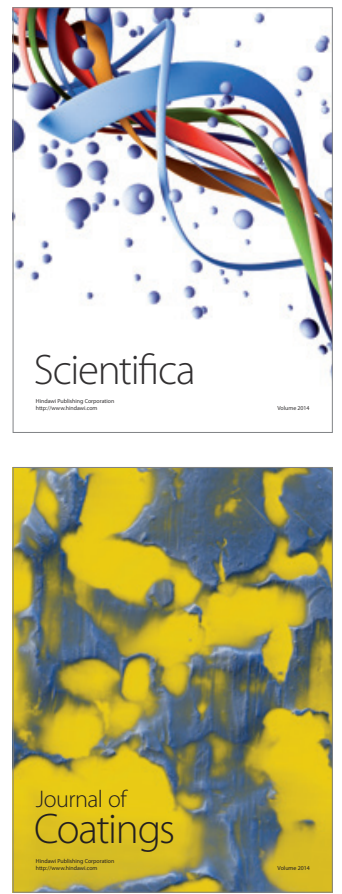
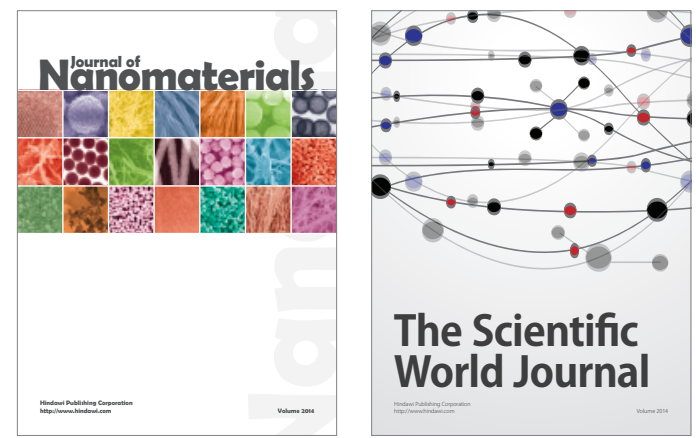

The Scientific World Journal
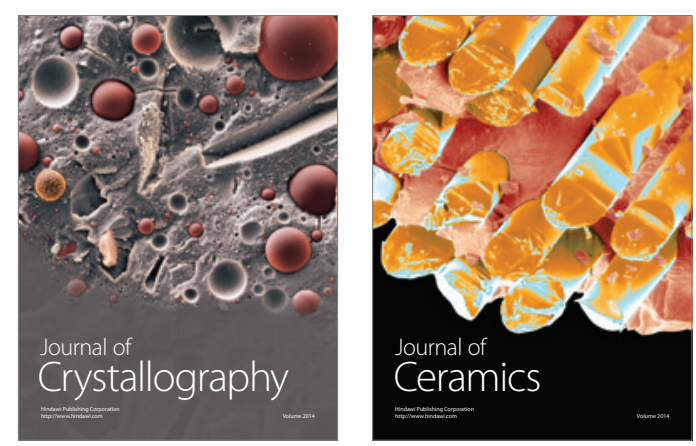
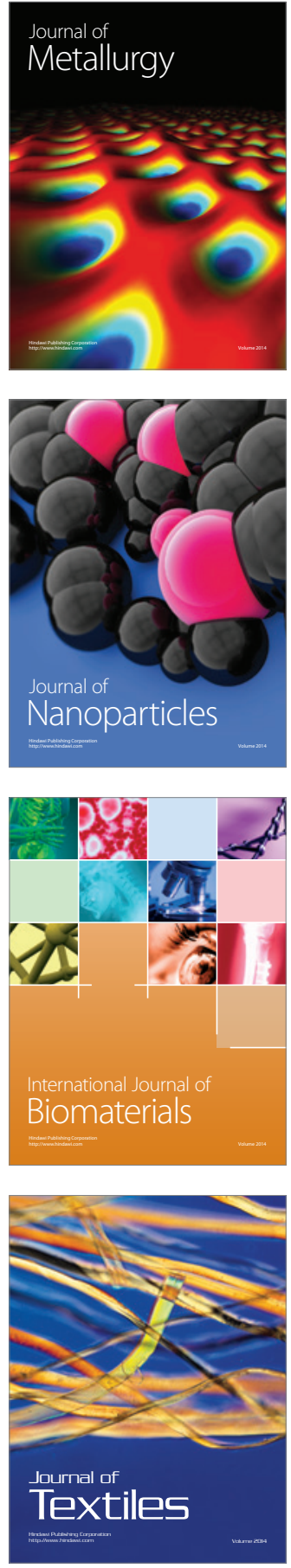